\title{
COMPUTERIZED AXIAL TOMOGRAPHY AND DIAGNOSIS OF MULTIPLE SCLEROSIS
}

\author{
PAULO R.M. BITTENCOURT, M.D., Ph.D. * \\ BRIAN E. KENDALL, F.R.C.P., F.R.C.R. **
}

Multiple sclerosis (M.S.) is a disease characterized by geographical distribution, higher incidence in young females and a variable clinical course, which often consists of acute exacerbation of neurological symptoms and periods of quiescence (McDonald, 1975). The pathology consists of multifocal demyelination more commonly in the optic nerves and chiasm, spinal cord, brainstem, adjacent to the lateral ventricles and in the periphery of the cortical gyri (Lumsden, 1970). Newly formed plaques display great cellular and enzyme activity throughout, while established active lesions display similar changes at the edges only and long-standing burn-out plaques consist almost exclusively of dense astrogliosis (Adams, 1975). Although it is widely accepted that exacerbation and remission of M.S. are temporally related to evolution of the plaques, routine clinico-morphological correlation was impossible prior to computed axial tomography (C.T.). Acute plaques more than $2 \mathrm{~cm}$ in diameter had been demonstrated by increased isotope uptake on gamma encephalograms (Antunes et al, 1974), but the appearances were not specific.

This report illustrates the spectrum of C.T. abnormalities observed in M.S., including the less commonly reported contrast-enhancing low density hemispherical lesions caused by acute plaque formation which may give rise to diagnostic difficulties.

\section{CASE REPORTS}

Case 1 (H.MCE.) - A 60-year old male had been well until ten years previously when he first noticed difficulty finding correct words when under stress. Two years later he began to drag his left leg when walking and after a further 6 months his gait became unsteady. On a previous admission to The National Hospital em 1975, he displayed mild dysphasia, dysarthria and ataxia of gait. There were mild left-sided limb ataxia, pyramidal weakness, hyper-reflexia and bilateral extensor plantars. Routine haematological and biochemical blood tests, cerebrospinal fluid analysis, E.E.G., gamma scan and routine radiology were normal. A Myodil myeologram was normal. C.T. scan showed mild cortical cerebral atrophy. The patient was discharged without a definite diagnosis. He deteriorated slowly over the next 10 years and needed crutches by 1978 . On

From the Lysholm Department of Radiology, The National Hospital, Queen Square, London, United Kingdom: * neurologist; ** consultant radiologist.

Acknowledgements - The arthors wish to thank Professor J. Marshall and Dr. P. C. Gautier Smith (The National Hospital) and Dr. M. Harrison (The Middlesex Hospital) for allowing presentation of patients under their care. 
re-admission in November, 1981, general examination was unremarkable. There was ataxia of gait, dysarthria and bitemporal pallor of the optic discs. Bilateral internuclear ophthalmoplegia, dysmetric saccades and broken smooth pursuit eye movements were noted. There was bilateral limb ataxia and pyramidal tract signs. Cerebrospinal fluid protein was $60 \mathrm{mg} / 100 \mathrm{ml}$. Protein electrophoresis showed an oligoclonal pattern. Visual evoked responses showed symmetrical delay. C.T. scan showed enlargement of the lateral and third ventricles with prominent cerebral cortical sulci and Sylvian fissures. Multiple low density lesions were present adjacent to the lateral ventricles (Figures 1 and 2). The patient was discharged with a diagnosis of «progressive probable» M.S. (MacDonald, 1975).

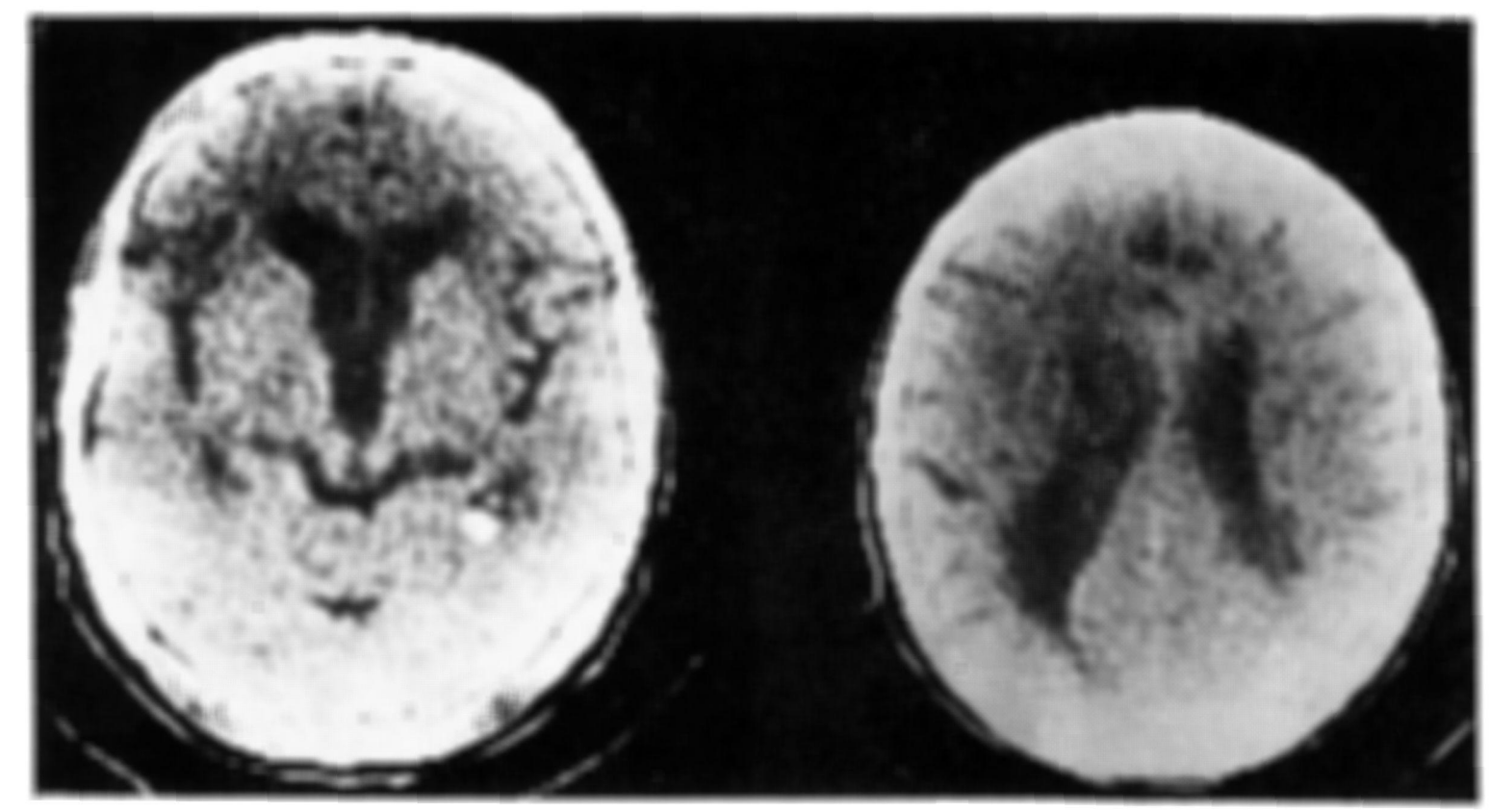

Figure 1 - Case 1. Plain CT scan (EMI 1010), sections through the lateral ventricles ( $a$ and $b$ ). The lateral and third ventricles are enlarged and cerebral sulci and Sylvian fissures are prominent. There are low density plaques adjacent to the right frontal horn and both trigones.

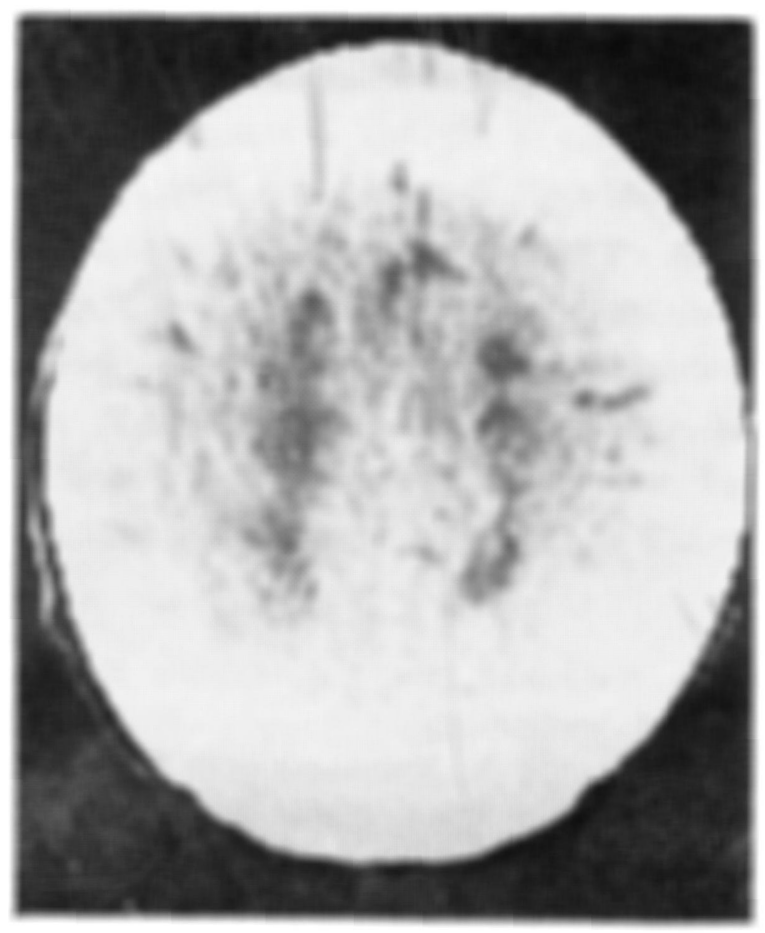

Figure 2 - Case 1. Highter section, at the level of the roof of the lateral ventricles. Multiple low density plaques are shown, more evident adjacent to the right lateral ventricle. 
Case 2 (MEC) - A 28-year old female had been well until 2.5years previously, when after an episode of arthralgia, she developed numbness of the left shoulder, followed by weakness of left leg, unsteady gait and severe lethargy. These symptoms appeared over a period of two weeks and precipitated admission to another hospital in March, 1979. General physical examination was unremarkable. Cranial nerves were normal. There was bilateral limb ataxia and left-sided pyramidal tract signs. Light touch, pinprick and vibration sensations were decreased on the left arm. Routine blood tests, virological screen, Kveim test, serology and immunological studies were all normal. Paul Bunnell screen test was positive. Cerebrospinal fluid protein was $73 \mathrm{mg} / 100 \mathrm{ml}$ (IgG $=7 \mathrm{mg} / 100 \mathrm{ml}$ ). Radio-isotope studies of bone and liver, biopsy of liver, muscle and jejunum, radiology of skull, spine, renal and gastro-intestinal tracts were ncrmal. C.T. scan (20-03-1979) showed a number of low density well demarcated lesions in both hemispheres which enhanced markedly after intravenous contrast (Figure 3). Visual evoked responses were normal. While in hospital the patient developed diarrhoea, signs of respiratory tract infection, cervical lymphadenopathy and her neurological state deteriorated with upper neurone right facial weakness, pyramidal signs on the right leg and ataxia of gait. Over the next few weeks she impreved steadily but still complained of malaise and tiredness when discharged in late April, 1979, with a diagnosis of possible encephalitis related to infectious mononucleosis. In August, 1979, she was re-admitted to the same hospital with ill-defined malaise. Pallor of the left optic disc and fine horizontal nystagmus to the left were noted. C.T. (3-9-79) showed regression of most of the previously noted enhancing low density lesions (Figure 4). General malaise, lethargy, irritability and lability of mood persisted for the following 20 months. She presented to The National Hospital in June, 1981, with a 2-month history of increasing dizziness on turning the head to either side or when lying down. One week before admission she had suddenly become «cross-eyed» and unable to move her eyes. General examination was unremarkable. There

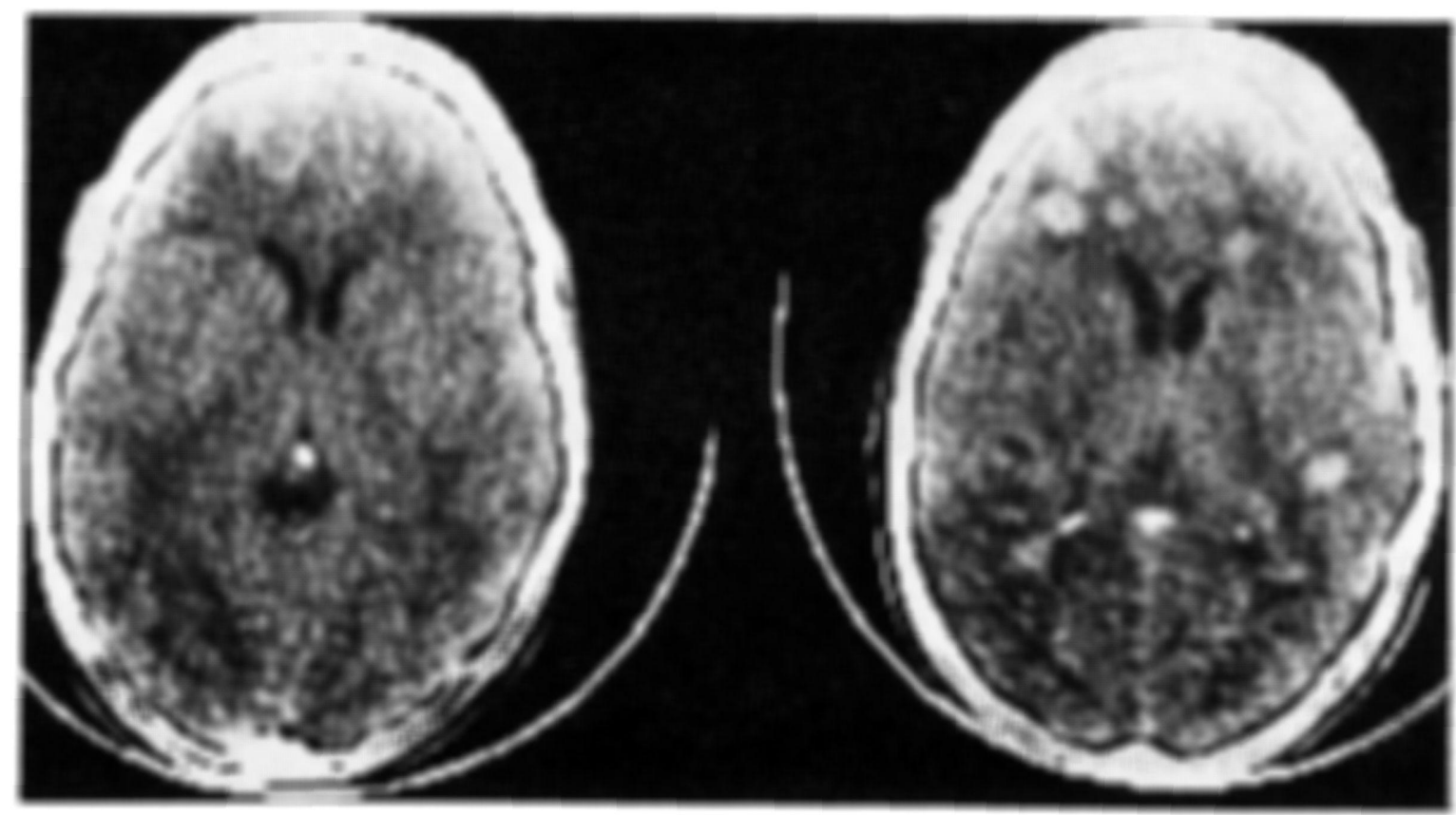

Figure 3 - Case 2. Plain (a) and enhanced (42 $g$ iodine, b) CT scans (EMI 1010). There are multiple small enhancing low densities in the white matter, most prominient in the left frontal lobe (81-2-1979). 


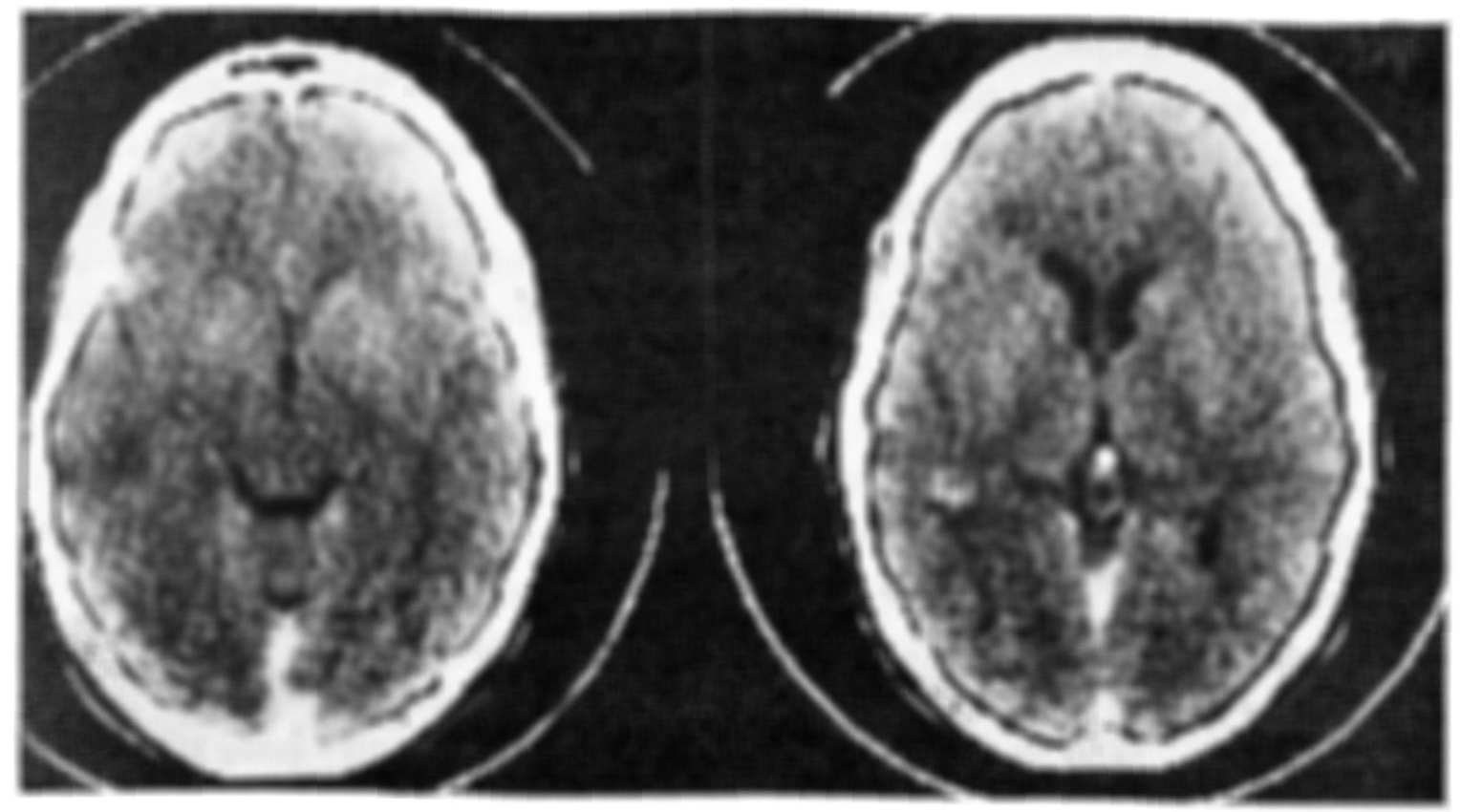

Figure $4-$ Case 2. Similar sections after enhancement showing regression of the lesions (3-9-1979).

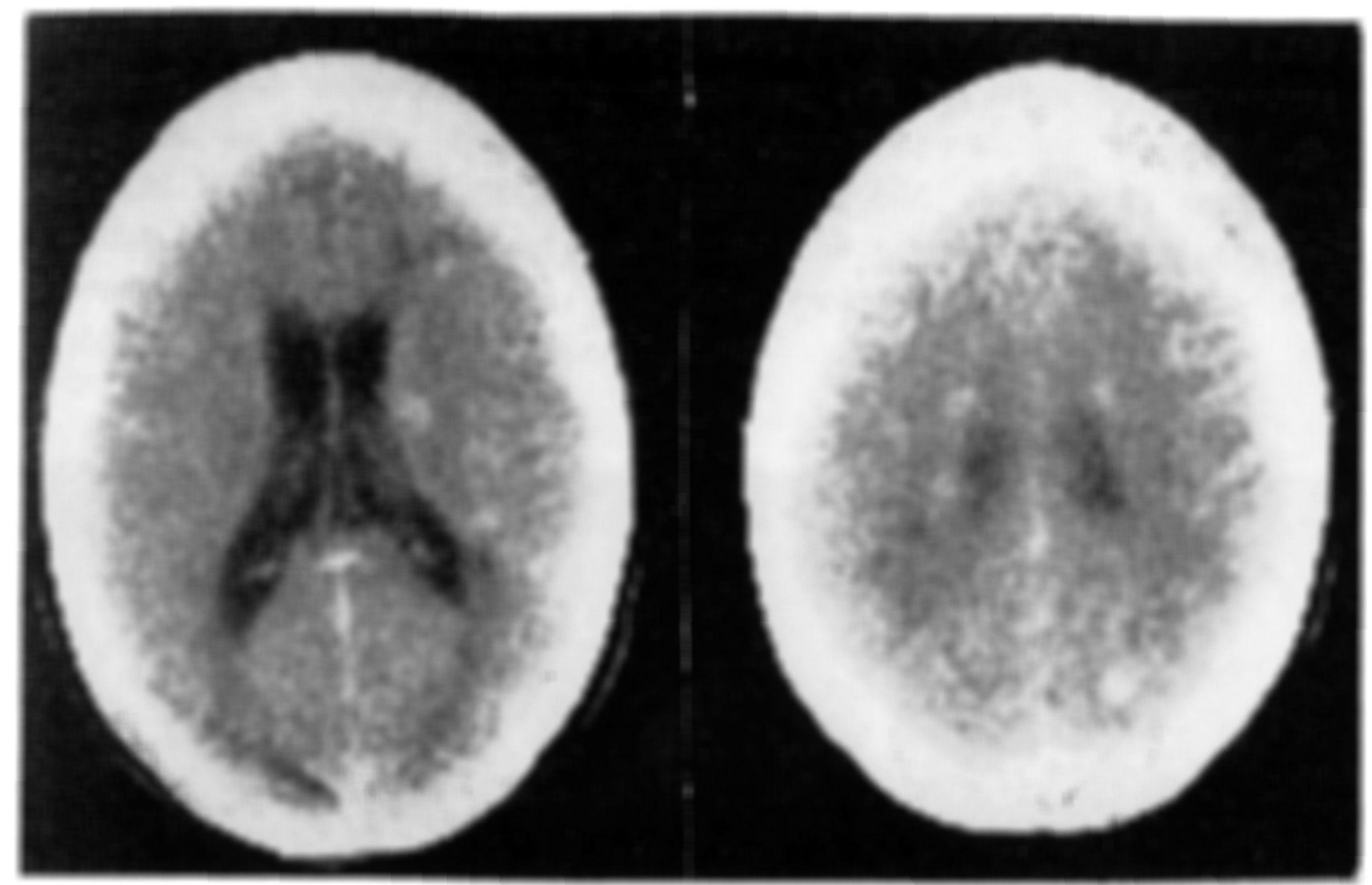

Figure 5 - Case 2. Enhanced CT scan (EMI 5005). Multiple enhancing low densities are again present in the white matter, most prominent adjacent to the lateral ventricles (15-7-1981).

was slight dragging of the legs and ataxia of gait. Both optic discs were pale. In the resting position both eyes were held in internal squint with severe limitation of eye movements, both «doll's head» and voluntary, and gaze paretic nystagmus to the right left and upwards. There was mild ptosis, decreased blinking rate and an upper neurone facial weakness on the right. In the limbs there was bilateral ataxia with 
pyramidal signs. Routine blood tests, immunological and serological investigations were normal. Cerebrospinal fluid protein was $64 \mathrm{mg} / 100 \mathrm{ml}$. Protein electrophoresis showed an oligoclonal pattern. Visual evoked responses were unsatisfactory because of the position of the eyes. Auditory evoked responses to click stimuli showed small amplitude and varying latency of components III and V. Skull and chest $x$-Rays were normal. C.T. Scan (15-7-1981) showed a number of low density contrast enhancing lesions in both hemispheres, mainly adjacent to the lateral ventricles (Figure 5). The patient was discharged with a diagnosis of «definite» M.S. (McDoriald, 1975).

Case 3 (RS) - A 48-year old male had been well until June, 1980, when he suddenly developed progressive slurring of speech followed by blurring of vision when looking straight ahead and occasional double-vision. Later in June, 1980, he noted dribbling from the right side of the mouth and was admitted to a local hospital where his condition deteriorated. Physical examination revealed severe dysarthria, right upper
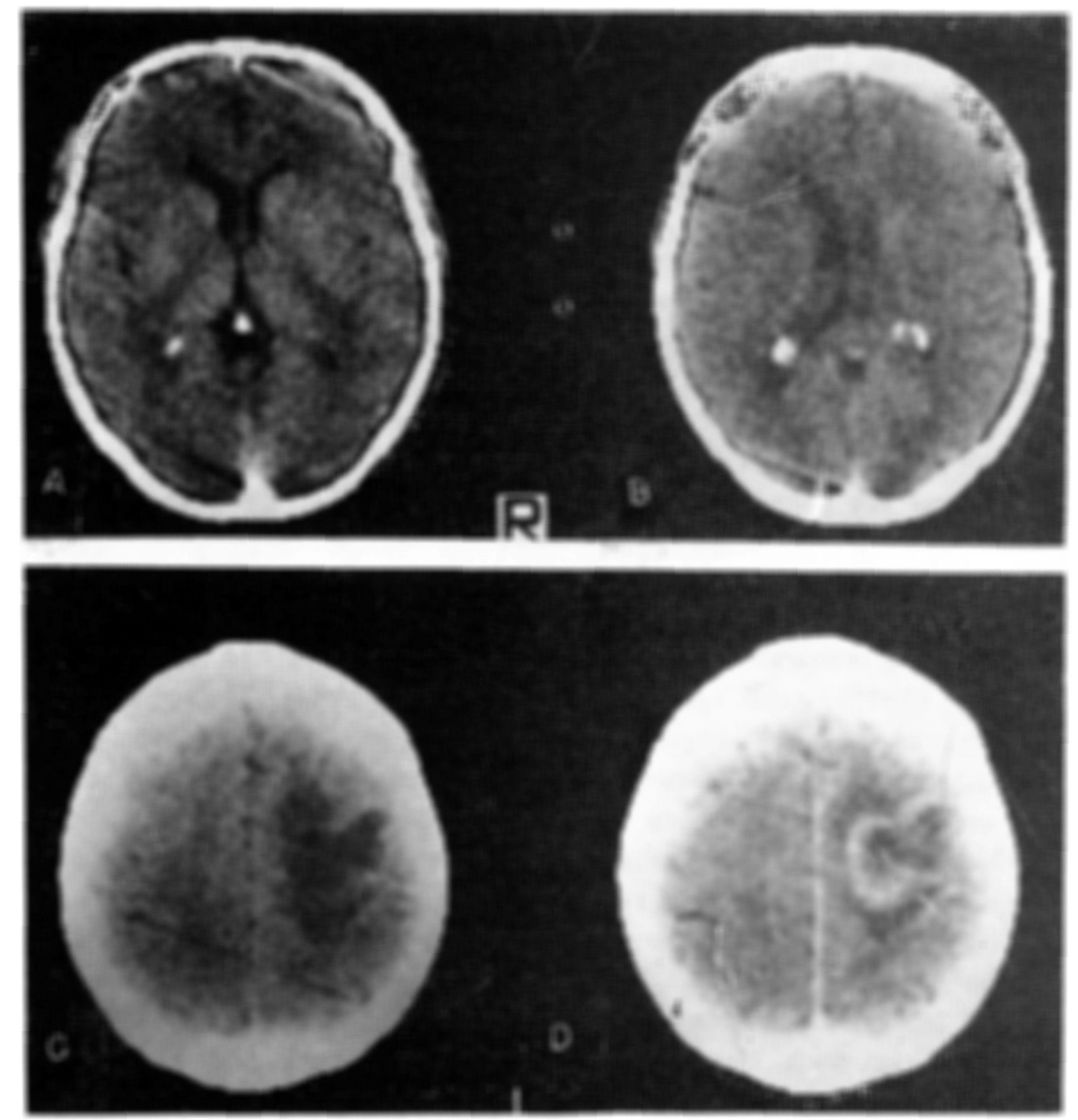

Figure 6 - Case 3. Plain (a,b,c,) and enhanced (d) CT scans (EMI 5005). There is a large low density lesion having ring enhancement, which compresses the anterior part of the body and the frontal horn of the right ventricles. 
neurone facial weakness, nystagmus on lateral gaze to the right and left and bilateral limb ataxia. Routine haematological and biochemical blood tests were normal. Cerebrospinal fluid analysis showed a protein of $150 \mathrm{mg} / 100 \mathrm{ml}$, with normal cells and sugar. He was admitted to The Middlesex Hospital in early July, 1980, where general physical examination was unremarkable. He was mentally and physically slow and cried frequently during the examination. There was severe dysarthria and truncal ataxia. Partial left internuclear ophthalmoplegia, limitation of up-gaze, broken smooth-pursuit and gaze paretic nystagmus in all directions were noted. There was bilateral partial ptosis and a right upper neurone facial weakness. Bell's phenomenon was absent bilaterally. The jaw jerk was brisk and there were bilateral pyramidal tract signs and ataxia in the limbs. The glabellar tap and the right palmomental reflex were present. Routine haematological, biochemical and serological tests and virological screen were negative. E.E.G., echocardiography and plain and contrast enhanced C.T. scans were non-contributory. A diagnosis of «probable» M.S. was made (McDonald, 1975). Over the next two weeks the patient improved steadily on dexamethazone and by the time of discharge there was mild gait and limb ataxia with minimal right facial weakness. The internuclear ophthalmoplegia had disappeared. He remained well until October, 1980, when he was re-admitted with confusion, slurred speech, difficulty using the hands and severe left hemiparesis with bilateral extensor plantars. Routine haematological, biochemical and serological blood tests, visual evoked responses and plain radiology were normal. C.T. scan (Figure 6) showed a large, low density lesion which showed ring enhancement after intravenous contrast nsedium, above and lateral to the frontal horn and anterior part of the body of the right lateral ventricle. The lesion was surrounded by oedema and produced compression of the body and frontal horn of the right lateral ventricle. Cerebral biopsy through a right parietal burr-hole showed evidence of a demyelinating process, confirming the diagnosis of M.S. There was no response to dexamethazone and the patient died in December, 1980: autopsy was not permitted.

\section{DISCUSSION}

The objective clinical criteria for the diagnosis of M.S. were reviewed by McDonald (1975), who concluded that although the diagnosis could only be proven by biopsy or at post-mortem examination, a "definite" diagnosis could be made on evidence of two or more episodes or relapse with subsequent remission, especially when lesions were anatomically unrelated. In those cases of M.S. which follow a slowly progressive course without obvicus exacerbation and remission, a "progressive probable" diagnosis can be established when there is evidence of two or more independent lesions of the central nervous system. The clinical diagnosis may be impossible in cases with a single demonstrated lesion. A number of investigations used to detect latent plaques can be helpful in such circumstances, including visual and auditory evoked responses and cerebrospinal fluid protein electrophoresis (Halliday et al, 1972; Robinson and Rudge, 1975; Tourtellotte, 1975). None of the cases presented here could be diagnosed when they first presented to medical attention. Patient 1 was diagnosed as "progressive probable" M.S. 10 years after onset, while patient 2 was considered "definite" M.S. 2.5 years after onset of symptoms. 
Patient 3 had a rapidly progressive course and although he could be diagnosed as "definite" at the second relapse, cerebral biopsy was undertaken because of the unusual C.T. appearance.

In recent years it has become clear that a large number of patients display C.T. abnormalities which may support the diagnosis of M.S. Gyldensted (1976) studied 110 patients with clinically definite or probable M.S. of duration between 1-45 years (mean 17). He found that 36\% showed sharply demarcated areas of low density around the lateral ventricles, thought to represent the periventricular plaques of demyelination almost universally present at post-mortem examination (Lumsden, 1970). Neither age at onset nor duration of the disease appeared to be related to the detection of the plaques by CT (Gyldensted, 1976). Contrast medium was given to $18 \%$ of the cases, but no additional lesions were shown. There was no abnormal enhancement, suggesting the plaques were inactive. Cerebral atrophy was present in over $\mathbf{7 5 \%}$ of cases and less than $25 \%$ had normal scans. These observations were generally supported by the findings of Radue and Kendall (1978), who found plaques in $23 \%$ of 47 cases, using second generation scanners. They were able to demonstrate further low density lesions in two patients examined with xenon enhancement. The C.T. appearance of case 1 of this report is similar to those described by Gyldensted (1976), in that approximately 10 years after the onset of symptoms there is evidence of mild cortical and central cerebral atrophy, as well as the more specific low density lesions adjacent to the lateral ventricles. These appearances can be considered typical of chronic, long-standing M.S. (Gyldensted, 1976; Radue and Kendall, 1978; Hershey et al, 1978). Case 2 had a strikingly different C.T. presentation in that one month after onset of symptoms there were multipie sharply demarcated low densities which enhanced homogeneously after intravenous administration of contrast (Figure 3). Six months later, during a period of partial remission, the lesions were less evident (Figure 4), but within two months of the onset of the following relapse multiple lesions were again nuted (Figure 5). The observations support recent suggestions that these enhancing low densities represent active, acute sites of demyelination (Aita et al, 1978; Morariu et al, 1980). Only a small number of patients have been described in which either small isodense or low density areas enhanced homogeneously after intravenous contrast (Cole and Ross, 1977; Harding et al, 1978; Radue and Kendall, 1978; Hershey et al, 1978; Sears et al, 1978; Lebow et al, 1978; Aita et al, 1978; Morariu et al, 1980; case 2 of the present report). Without exception these enhancing lesions were found in female patients during acute relapses of symptoms. Although most reports offer follow-up of only a few months after demonstration of the plaques, these patients had relatively severe forms of M.S., with major residual neurological deficits.

An unusual presentation of acute M.S. has been recently described in two patients (Van der Velden et al, 1979; Nelson et al, 1981). As in case 3 of the present report, C.T. demonstrated a single large low density area in the cerebral hemispheres, with ring enhancement, surrounding oedema and compression of midline structures. The lesion was demonstrated between 4 months 
and 4 years after onset of symptoms, in patients aged between 38-60 years. Histological confirmation of the diagnosis was necessary in all 3 patients and prognosis was poor, two of the cases being dead within a few months of the C.T. demonstration of the lesion (Van der Velden et al, 1979; Nelson et al, 1981; case 3 of the present report). In only 3 of 20 cases of acute M.S. for which there are adequate topographic data in the literature were there more than two enhancing plaques (Cole and Ross, 1977; Radue and Kendall, 1978; Harding et al, 1978; Hershey et al, 1978; Aita et al, 1978; Sears et al, 1978; Lebow et al, 1978; Van der Velden et al, 1979; Morariu et al, 1980; Nelson et al, 1981). In one patient with a rapidly progressive course to death in 9 months autopsy revealed a much greater number of plaques than were seen on C.T. (Lebow et al, 1978). In a study of low density plaques in two cadaver brains Haughton et al (1979) were able to demonstrate by C.T. only $20 \%$ of autopsy proven plaques with a modern scanner using $5 \mathrm{~mm}$ sections. Plaques smaller than $7 \mathrm{~mm}$ could not be visualised on C.T. A greater resolution in terms of identifying plaques is possible with nuclear magnetic resonance imaging (Young et al, 1981). The apparent correlation between clinical relapse and degree of enhancement of plaques was used by Sears et al (1978) to demonstrate the effects of steroid therapy on M.S., but since the rate of change in enhancement pattern without therapy is not known (Aita et al, 1978), claims of steroid efficacy need to be supported by controlled trials.

The main differential diagnosis of the C.T. presentation of chronic M.S. as exemplified by case 1 is subcortical arteriosclerotic encephalopathy (Binswanger type), in which low density in the deep hemisphere white matter, most prominent on the frontal lobes, mild cerebral atrophy and multiple small infarcts (lacunes) are the hallmarks (Loizou et al, 1981). Onset is generally later in life than M.S., and other signs of arteriosclerotic disease such as dementia and reduced cerebral blood flow are usual (Loizou et al, 1981). Symmetrical generalized or focal low densities which occur in several conditions which usually present in children, including leukodystrophies, mucopolysaccharidoses, gangliosidoses, mitochondrial cytopathies and neurodegenerative processes such as those associated with pigmentary degeneration of the retina and myopathy (Kendall, 1979; Egger and Kendall, 1981), are unlikely to be confused with M.S. The densities of M.S. are asymmetrical, multifocal and tend to be sharply delineated; involvement of the basal ganglia is unusual and calcifications do not occur. Rarely, ill-defined periventricular low densities may be shown in patients with increased cerebrospinal fluid pressure, without other manifestations of hydrocephalus (Moseley and Radue, 1979). Multiple enhancing low density lesions occur in several other disease processes. The appearance of plaques may be closely simulated by small ischaemic infarcts and rarely by encephalitis or cysticercosis (Aulich et al, 1976; Carbajal et al, 1977; Constant et al, 1977). Claveria et al (1977) found enhancement in $94 \%$ of 130 cases of metastatic disease, but as in the case of tuberculomata, differentiation from the great majority of acute M.S. patients is readily made by associated C.T. features which include non-homogeneous enhancement patterns, surrounding oedema and mass effect (Claveria et al, 1977; Kendall et al, 1979). 
Only rarely as in case 3 of this report and two sthers in the literature (Van der Velden et al, 1979; Nelson et al, 1981) do physicians have to resort to cerebral biopsy to confirm the diagnosis. A single large low density region with ring enhancement and considerable mass effect is indistinguishable from a malignant neoplasm though in two other patients with a similar C.T. picture studied by the authors, there had been previously documented episodes of demyelination which supported the correct diagnosis. Nonetheless, the features of plaque location adjacent to the lateral ventricles and cerebral cortex, and in acute cases, the continuing change in pattern of enhancement with acute remissions and relapses of symptoms, are unique to M.S. Such typical C.T. appearances may establish the diagnosis in patients presenting with an isolated optic neuropathy or spinal cord syndrome, or in those in the first severe exacerbation of cerebral symptoms. Recognition of M.S. on C.T. may render more invasive procedures such as angiography or cerebral biopsy unnecessary.

In conclusion, review of the literature suggests that there are 3 main C.T. presentations of M.S. which are illustrated by our examples. Varying degrees of cerebral atrophy frequently associated with multiple low density nonenhancing hemispheric plaques are seen in patients with chronic, slowly progressive M.S. Single or multiple enhancing low densities are seen in younger patients during acute relapses of more severe forms of M.S. Large enhancing plaques with surrounding oedema and mass effect have been reported in only 3 cases, and are apparently associated with a poor prognosis.

\section{SUMMARY}

Computed axial tomography (C.T.) findings are illustrated in 3 patients who presented with C.T. changes suggesting respectively chronic M.S., acute M.S., and an appearance simulating a malignant tumour. Review of the literature shows that the chronic form with cerebral atrophy and low density lesions in the hemispheres is common in patients with a long history and is unlikely to cause diagnostic difficulty. The acute presentation is less common and could be confused with a variety of causes of multiple low density enhancing lesions. The C.T. diagnosis of M.S. is more difficult in rare cases in which plaques cause mass effect and show ring enhancement; all 3 such cases in the literature were subjected to cerebral biopsy.

\section{RESUMO}

Tomografia axial computadorizada e diagnóstico de esclerose múltipla.

Os achados na tomografia axial computadorizada (C.T.) são descritos em 3 pacientes com esclerose múltipla (M.S.) que tiveram C.T. sugestiva de M.S. crônica, aguda e aguda simulando tumor cerebral. Revisão da literatura mostra que a forma crônica, com atrofia cerebral e lesões de baixa densidade nos hemisférios cerebrais, é comum em pacientes com longa história de M.S., e não deve causar dificuldade diagnóstica. A apresentação aguda é menos comum 
e pode ser confundida com várias causas de lesões de baixa densidade que acumulam contraste intravenoso homogeneamente. $\mathrm{O}$ diagnóstico por C.T. é especialmente difícil quando as placas de desmielinização causam efeito de massa com deslocamento de estruturas cranianas mediais, e padrão em anel após injeção intravenosa de contraste. De 3 casos da literatura incluindo um apresentado neste trabalho, todos necessitaram biópsia cerebral para excluir causas tratáveis.

\section{REFERENCES}

1. ADAMS, C. W. M. - The onset and progression of the lesion in multiple sclernsis. In DAVIDSON, A. N.; HUMPHREY, J. G.; LIVERSEDGE, A. L.; McDONALD, W. I. \& POTTERFIELD, J. S. (eds.) - Multiple Sclerosis Research. HM Stationery Office. London, 1975, pg. 92.

2. AITA, J. F.; BENNET, D. R.; ANDERSON, R. E. \& ZITER, F. - Cranial CT appearance of acute multiple sclerosis. Neurol. (Minneapolis) 26:252, 1978.

3. ANTUNES, J. L.; SCHLESINGER, E. B. \& MICHELSEN, W. J. - Abnormal brain scan in demyelinating diseases. Arch. Neurol. (Chicago) 31:269, 1974.

4. AULICH, A.; LANGE, S.; STEINHOFF, H.; SCHINDLER, E. \& WANDE, S. Diagnosis and follow-up studies in brain abscess using computerized tomography. In LANKSCH, W. \& KAXNER, E. (eds.) - Cranial Computerized Tomography. Springer-Verlag. Berlin, 1976, pg. 366.

5. CARBAJAL, J. R.; PALACIOS, E.; AZAR-KIA, B. \& CHURCHILL, R. Radiology of cysticercosis of the central nervous system including computed tomugraphy. Radiol. 125:127, 1977.

6. CLAVERIA, L. E.; KENDALL, B. E. \& Du BOULAY, G. H. -- Computerized axial tomography in supratentorial gliomas and metastases. In Du BOULAY, G. H. \& MOSELEY, I. F. (eds.) - Computerized Axial Tomography in Clinical Practice. Springer-Verlag. Berlin, 1977, pg. 85.

7. COLE, M. \& ROSS, R. J. - Plaque of multiple sclerosis seen on computerized trans-axial tomogram. Neurol. (Minneapolis) 27:890, 1977.

8. CONSTANT, P.; RENOU, A. M.; CAILle, J. M. \& VERNhIET, J. - C. A. T. studies of cerebral ischaemia. In Du BOULAY, G. H. \& MOSELEY, I. F. (eds.) Cornputerized Axial Tomography in Clinical Practice. Springer-Verlag. Berlin, 1977, pg. 85.

9. EGGER, J. \& KENDALL, B. E. - Computed tomography in mitochondrial cytopathy. Neuroradiol. 22:73, 1981.

10. GYLDENSTED, C. - Computer tomography of the cerebrum in multiple sclerosis. Neuroradiol. 12:34, 1976 .

11. HALLIDAY, A. M.; McDONALD, W. I. \& MUSHIN, J. - Delayed visual evoked response in optic neuritis. Lancet $1: 982,1972$.

12. HARDING, A. E.; RADUE, E. W. \& WHITELEY, A. M. - Contrast-enhanced lesions on computerized tomography in multiple sclerosis. J. Neurol. Neurosurg. Psychiat. 41:754, 1978.

13. HaUghtoN, V. M.; HO, K. C.; WILliams, H. L. \& ELDEVILL, O. P. - CT detection of demyelinating plaques in multiple sclerosis. Am. J. Roentgenol. $132: 213,1979$.

14. HERSHEY, I. A.; GADO, M. H. \& TROTTER, J. L. - Computerized tomography in the diagnostic evaluation of multiple sclerosis. Ann. Neurol. 5:32, 1979.

15. KENDALL, B. E. - Symmetrical white matter low attenuation in children. $X$-tract $7: 3,1979$.

16. KENDALL, B. E.; JAKUBOWSKI, J.; POLLICINO, P. \& SYMON, L. - Difficulties in diagnosis of supratentorial gliomas by CAT scan. J. Neurol. Neurosurg. Foychiat. 42:485, 1979.

17. LEBOW, S.; ANDERSON, D. C.; MASTRI, A. \& LARSON, D. - Acute multiple sclerosis with contrast-enhancing plaques. Arch. Neurol. (Chicago) 35:435, 1978. 
18. LOIZOU, L. A.; KENDALL, B. E. \& MARSHALL, J. - Subccrtical arteriosclerotic encephalopathy: a clinical and radiological investigation. J. Neurol. Neurosurg. Psychiat. 44:294, 1981.

19. LUMSDEN, C. E. - The neuropathology of multiple sclerosis. In VINKEN, P. J. \& BRUYN, G. W. (eds.) - Handbook of Clinical Neurology 9:217. North-Holland Publ. Co. Amsterdam, 1970.

20. McDONALD, W. I. - What is multiple sclerosis? Clinical criteria for diagnosis. In DAVISON, A. N.; HUMPHREY, J. G.; LIVERSEDGE, A. L., MCDONALD, W. I. \& PORTERFIELD, J. S. (eds.) - Multiple Sclerosis Research. HM Stationery Office. London, 1975 , pg. 1.

21. MORARIU, M. A.; WILKINS, D. E. \& PATEL, S. - Multiple sclerosis and serial computerized tomography: delayed contrast enhancement of acute and early lesions. Arch. Neurol. (Chicago) 37:189, 1980.

22. MOSELEY, I. F. \& RADU, E. W. - Factors in influencing the development of periventricular lucencies in patients with raised intracranial pressure. Neuroradiol. $17: 65,1979$.

23. NELSON, M. J.; MilleR, S. L.; McLAIN, L. W. \& GOLD, L. H. A. - Multiple sclerosis: large plaque causing mass effect and ring sign. J. comput. assist. Tomogr. 5:892, 1981.

24. RADU, E. W. \& KENDALL, B. E. - Iodide and xenon enhancement of computed tomography in multiple sclerosis. Neuroradiol. 15:153, 1978.

25. ROBINSON, K. \& RUDGE, P. - Auditory evoked responses in multiple sclerosis. Lancet $1: 1164,1975$.

26. SEARS, E. S.; TINDALL, R. S. A. \& ZARNOW, H. - Acute multiple sclerosis: enhanced computerized tomographic imaging of lesions and the effect of cortico-steroids. Arch. Neurol. (Chicago) 35:426, 1978.

27. TOURTELLOTE, W. W. - What is multiple sclerosis? Laboratory criteria for diagnosis. In DAVISON, A. N.; HUMPHREY, J. G.; LIVERSEDGE, A. L.; McDONALD, W. I. \& POTTERFIELD, J. S. (eds.) - Multiple Sclerosis Research. HM Stationery Office. Lendon, 1975, pg. 9.

28. Van der VELDEN, M.; BOTS, G. T. A. M. \& ENDTZ, I. J. - Cranial CT in multiple sclerosis showing a mass effect. Surg. Neurol. 12:307, 1979.

29. YOUNG, R.; HALL, A. S.; PALLIS, C. A.; LEGG, N. J.; BYDDER, G. M. \& STEINER, R. E. - Nuclear magnetic resonance imaging of the brain in multiple sclerosis. Lancet 1:1063, 1981.

30. ZEE, C.; SEGALL, H. D.; MILleR, C.; TSAI, F. Y.; TEAL, J. S.; HIEShima, G.; AHMADI, J. \& HALLS, J. - Unusual neuroradiological features of intracranial cysticercosis. Radiol. 137:397, 1980.

Dcpartamento de Clinica Médica (Neurologia) - Hospital de Clínicas - Rua General Carneiro 180 - 80000 Curitiba, PR - Brasil. 